\title{
Perceptions of Audience on Soundpainting Performance
}

\author{
Sonat Coskuner \\ Correspondence: Sonat Coskuner, Ondokuz Mayıs University, Education Faculty, Music education Department, Samsun, \\ Turkey.
}

$\begin{array}{lcc}\text { Received: July 16, } 2018 & \text { Accepted: August 28, } 2018 & \text { Online Published: August 29, } 2018 \\ \text { doi:10.11114/jets.v6i10.3445 } & \text { URL: https://doi.org/10.11114/jets.v6i10.3445 }\end{array}$

\begin{abstract}
Today, contemporary music emerges as an experimental phenomenon trapped in the laboratory environment rather than an element of skill. Modern music, where principles such as specialism and rationality are determinative, has become difficult to understand not only for performers who carry it on the stage but also for today's audience. One of the works done in recent years is Soundpainting, which is based on improvisation and allows everyone to do this stage art. Soundpainting is the multidisciplinary live composing sign language for Musicians, Dancers, Actors and Visual Artists. Presently the language comprises more than 1750 gestures that are signed by the Soundpainter to indicate the type of material desired of the performers. The Soundpainter (the composer) standing in front (usually) of the group communicates a series of signs using hand and body gestures indicating specific and/or aleatoric material to be performed by the group. The Soundpainter develops the responses of the performers, molding and shaping them into the composition. In this research, it is aimed to determine the perceptions of the audiences who are listeners in a Soundpainting performance and at the same time performers in Soundpainting performance. The specify of this perception is important in terms of determine the attitude of the listeners fort he first time involved in the Soundpainting performance as well as bringing solutions to the problem of music and alienation from a different point of view.
\end{abstract}

Keywords: soundpainting, audience, musical performance, perception, aleatoric music

\section{Introduction}

Although it is predominantly carried out in certain European countries, Soundpainting is not (has not) enough recognized yet. Soundpainting, which is mostly performed as a stage art, has recently been the subject of scientific studies. What is Soundpainting? Soundpainting is the multidisciplinary live composing sign language for Musicians, Dancers, Actors and Visual Artists. Presently the language comprises more than 1750 gestures that are signed by the Soundpainter to indicate the type of material desired of the performers. The Soundpainter (the composer) standing in front (usually) of the group communicates a series of signs using hand and body gestures indicating specific and/or aleatoric material to be performed by the group. The Soundpainter develops the responses of the performers, molding and shaping them into the composition (Thompson, 2015: 4).

In general, soundpainting performance begins with a series of phrases that describe the basic elements of music such as loudness, pitch, tempo and sound material in the direction of a equipped Soundpainter's composition. A Soundpainting collective in time, they can interpret more complex signs as they learn the language and gain fluency.

We can think of this stage art that emerged in the last quarter of the 19th century, in contemporary music class. Briefly, "contemporary music is a period of international art music that develops from the end of the nineteenth century (romantic period) to the present day, and the composing currents and techniques that developed during this period" (Yöre, 2011: 4).

Soundpainting is a simultaneous composing environment for Soundpainter, with a new improvisation area for performers. On the one hand Soundpainter and performers are part of this stage art, on the other hand the role of the audience, last ring of the chain is a matter of curiosity.

With the emergence of contemporary music, breaks began between the music itself and the audience. According to Selanik (1996), the fact that modern music has not been adopted by the great audiences is generally due to the incomprehensibility and complexity of this music (Cited. Dürük, 2009: 212). Today, controversies are still on the understanding of modern music. While some consider the difficult structure of understanding modern music as an ear problem to be overcome over time, others are driven by the technical issues leading to aesthetics and making the music 
incomprehensible. Kutluk (1997), stated that the reactions of the first contemporary music listeners who listened to the works of Debussy, Stravinsky and Schonberg in the first quarter of the 20th century "Okay, the music is over. So it's here. The accumulation of hundreds of years, that great wealth, universal harmony, genius, creativity, art, it is all over. They took the place of mess, cacophony, vilenes and rudeness" (Cited. Yöre, 2011: 4).

The opinions of the audience, one of the indispensable elements of the chain, are decisive for the composers of music from time to time. According to Ikonomova (1972: 123), the first and most important principle in the audiences' preferences is the pleasure principle. Because, pleasure is the main reason of some ones' adopting own kind of music and preferring another kind of music. Another reason why people choose specific music is the psychological effect of music. "As a branch of art and science, music is an effective part in the process of an individual's growth. It has a power, which may directly influence people's behaviors. A person becomes happy, sad, calm or aggressive depending on the type of music listened to" (Göncü, 2018: 46).

There are many ideas about how contemporary music can be understood and listened easily. One of these views is that Kalender, (2001: 151) expressed that the audiences must have information about musical elements, musical environments, composers in general, so that the music can be understood or easily perceived and resolved and music instruments' sound colors and technical characteristics, style knowledge, aesthetics, history of music can help in understanding by listening music.

In particular, Watt (1926) expressed his views on listening to new and unusual music as follows;" unfamiliar music gets very close attention if it is listened carefully. Interestingly, people should listen to any new music for two hours through five hours. The time under the lower limit is definitely wasted, and the ear thus develops by adapting more to the character of the contrary style (Cited. Coşkuner, 2016: 17).

Above, some suggestions are presented to make contemporary music easier to perceive. At this point, we can look for the answer to this question: what is perceptions and the factors that affect perception? According to Akarsu (1975: 16), perception is "the comprehend of that thing through the senses, directing attention to an object or phenomenon". Senemoğlu (2004: 293) basically divides the factors that affect the perception into two; 1) past experiences, pre-learners, 2) expectation. Subasi (2011: 378), who express perception as an interpretation or an interpretation process of sensory information, for the meaning of a stimulus, the individual must first have knowledge of that stimulus. Senemoğlu (2004: 293) describes this subject as "the individual is affected by mental organization, past experiences, level of motivation and many other internal factors".

\section{Problem of the research}

How are the perceptions of audiences Soundpainting performance?

\section{Sub-problems of the research}

1- What are the thoughts of audiences' for Soundpainting performance?

2- How are the audiences handling the Soundpainting performance in terms of psychological dimension?

3- How are the audiences handling the Soundpainting performance in terms of aesthetic dimension?

4- How are the audiences handling the Soundpainting performance in terms of sociological dimension?

5- How are the audiences handling the Soundpainting performance in terms of musical dimension?

\section{Aim of the research}

In this research, it is aimed to determine the perceptions of the audiences who are audiences in a Soundpainting performance and at the same time performers in Soundpainting performance.

\section{Importance of the research}

The research is important in determining the perceptions of audiences participating in Soundpainting performance for the first time. It is also thought that research will bring light to the researcher who wants to work in this area, and will bring a different perspective to the problem of music and alienation.

\section{Method}

\subsection{Model of the Research}

The research is a descriptive study based on screening and trial models for situational detection in terms of general purpose and method. "Scanning methods are the research approaches aiming at describing a situation, in the past or still present, as it is. Research subject incident, person or an object are aimed to be described within their own condition and as they are. They are not tried to change or be affected by any means. There is something asked to be known and it is there. What is important is to observe it in an appropriate way and to determine" (Karasar, 2004: 77). 


\subsection{Data Collection Tools and Analysis}

Qualitative information (data) used in the research was obtained through source screening and quantitative information was obtained by questionnaire. Qualitative information has been obtained from national and foreign sources that are directly or indirectly related to the subject. The questionnaire, which contains quantitative information, consists of 17 questions. The questionnaire prepared by the researcher consists of 5 point likert scale questions. The quantitative data obtained by means of data collection in the study are expressed as frequency (f) and percentage (\%).Expert opinion was received while the questions were being prepared. The questions were directed to 30 audiences who participate in the Soundpainting performance at the end of the first day of the "Intercultural Music, Conferences And Concerts" event organized in Samsun in 2018.

\section{Results}

What are the thoughts of audiences' for Soundpainting performance? Findings related to first sub-problem

Table 1. The responses of audiences to the expression "Soundpainting performance reflects today's experience"

\begin{tabular}{ccccccc}
\hline & Excessive & Quite & Partly & Few & None & Total \\
\hline $\mathrm{f}$ & 9 & 12 & 8 & 1 & - & 30 \\
\hline$\%$ & 30 & 40 & 26,7 & 3,3 & - & 100 \\
\hline
\end{tabular}

According to the table, $70 \%$ of audiences think that soundpainting performance reflects today's experience. We can say that the aleatoric materials during the performance dominate audiences' perceptions.

How are the audiences handling the Soundpainting performance in terms of psychological dimension? Findings related to second sub-problem

Six questions were asked to participants to answer this sub-question.

Table 2. The responses of audiences to the phrase "I felt happy during the Soundpainting performance"

\begin{tabular}{ccccccc}
\hline & Excessive & Quite & Partly & Few & None & Total \\
\hline $\mathrm{f}$ & 18 & 7 & 4 & 1 & - & 30 \\
\hline$\%$ & 60 & 23,1 & 13,3 & 3,3 & - & 100 \\
\hline
\end{tabular}

According to the table, $83 \%$ of audiences feel happy during the Soundpainting performance. It is possible to say that audiences give their opinion on this point because the performance of the Soundpainting is open to surprises and the audiences are part of this performance.

Table 3. The responses of audiences to the phrase "I felt angry during the Soundpainting performance"

\begin{tabular}{ccccccc}
\hline & Excessive & Quite & Partly & Few & None & Total \\
\hline $\mathrm{f}$ & 1 & - & 1 & 7 & 21 & 30 \\
\hline$\%$ & 3,3 & - & 3,3 & 23,1 & 69,3 & 100 \\
\hline
\end{tabular}

According to the chart, a large majority (94\%) of audiences participating in Soundpainting performance do not see themselves as angry during the performance.

Table 4. The responses of audiences to the phrase "I felt nervous during the Soundpainting performance"

\begin{tabular}{ccccccc}
\hline & Excessive & Quite & Partly & Few & None & Total \\
\hline $\mathrm{f}$ & 1 & 1 & 1 & 4 & 23 & 30 \\
\hline$\%$ & 3,3 & 3,3 & 3,3 & 13,3 & 76,8 & 100 \\
\hline
\end{tabular}

According to the table above, $90 \%$ of audiences feel very comfortable during performance. Soundpainting, contrary to performances which regular and auditory passivating, both the performer and the audience are more free. We can say that this leads to the perceptions of audiences.

Table 5. Responses of the audiences to the phrase "I'm disturbed by the sound during Soundpainting performance".

\begin{tabular}{ccccccc}
\hline & Excessive & Quite & Partly & Few & None & Total \\
\hline $\mathrm{f}$ & - & 1 & 2 & 4 & 23 & 30 \\
\hline$\%$ & - & 3,3 & 6,6 & 13,3 & 76,8 & 100 \\
\hline
\end{tabular}

According to the table, $90 \%$ of audiences are not disturbed by the sounds that are produced during performance. We may think that using chore pieces as a palette in the performance affects audiences' perceptions positively.

Table 6. The responses of audiences to the phrase "I felt free during the Soundpainting performance"

\begin{tabular}{ccccccc}
\hline & Excessive & Quite & Partly & Few & None & Total \\
\hline $\mathrm{f}$ & 20 & 8 & 1 & 1 & - & 30 \\
\hline$\%$ & 66 & 26,8 & 3,3 & 3,3 & - & 100 \\
\hline
\end{tabular}


According to the table above, as many as $93 \%$ of the audiences expressed they felt free during performance. Soundpainting philosophy removes the concept of mistake and leave the performers free creative field. We can say that audiences are experienced this free environment and that they gave a positive opinion.

Table 7. The responses of audiences to the phrase "I felt energetic during the Soundpainting performance"

\begin{tabular}{ccccccc}
\hline & Excessive & Quite & Partly & Few & None & Total \\
\hline $\mathrm{f}$ & 20 & 7 & 3 & - & - & 30 \\
\hline$\%$ & 66 & 23,5 & 9,9 & - & - & 100 \\
\hline
\end{tabular}

According to the table above, as many as $90 \%$ of audiences said they felt energetic during the Soundpainting performance. We can say that the performance of soundpainting is dynamic, open to surprises and interacting with the audience, making the audiences more energetic.

How are the audiences handling the Soundpainting performance in terms of aesthetic dimension? Findings related to third sub-problem

Three questions were asked to participants to answer this sub-question.

Table 8. The responses of audiences to the phrase "I found good during the Soundpainting performance"

\begin{tabular}{ccccccc}
\hline & Excessive & Quite & Partly & Few & None & Total \\
\hline $\mathrm{f}$ & 21 & 7 & 2 & - & - & 30 \\
\hline$\%$ & 69,6 & 23,8 & 6,6 & - & - & 100 \\
\hline
\end{tabular}

According to the table, $92 \%$ of audiences say that they found Soundpainting performance aesthetically good.

Table 9. The responses of audiences to the phrase "I found useful during the Soundpainting performance"

\begin{tabular}{ccccccc}
\hline & Excessive & Quite & Partly & Few & None & Total \\
\hline $\mathrm{f}$ & 19 & 6 & 5 & - & - & 30 \\
\hline$\%$ & 62,7 & 19,8 & 16,5 & - & - & 100 \\
\hline
\end{tabular}

According to the table, a large majority (82\%) of audiences find the Soundpainting performance as useful. Soundpainting minimizes the alienation between the audiences and the performers. We can say that this affects audiences' thoughts.

Table 10. Audiences' responses to "Soundpainting performance is universal".

\begin{tabular}{ccccccc}
\hline & Excessive & Quite & Partly & Few & None & Total \\
\hline $\mathrm{f}$ & 22 & 5 & 3 & - & - & 30 \\
\hline$\%$ & 72,6 & 16,5 & 9,9 & - & - & 100 \\
\hline
\end{tabular}

As shown in the table 10, nearly $89 \%$ of audiences think that Soundpainting performance is universal. We can think of the fact that the sign language is understood by everyone.

How are the audiences handling the Soundpainting performance in terms of sociological dimension? Findings related to fourth sub-problem

Five questions were asked to participants to answer this sub-question.

Table 11. Audiences responds to the phrase "I want to participate in Soundpainting collective".

\begin{tabular}{ccccccc}
\hline & Excessive & Quite & Partly & Few & None & Total \\
\hline $\mathrm{f}$ & 16 & 6 & 6 & 2 & - & 30 \\
\hline$\%$ & 52,8 & 19,8 & 19,8 & 6,6 & - & 100 \\
\hline
\end{tabular}

As shown in the table 11, as many as $72 \%$ of the concert audiences said they wanted to be in a Soundpainting collective. Soundpainting removes the borders and offers everyone a free improvisation area. It can be say that audiences are giving this opinion because they are experienced this performance in the concert and they were happy.

Table 12. Audiences responds to the phrase "I can not do Soundpainting".

\begin{tabular}{ccccccc}
\hline & Excessive & Quite & Partly & Few & None & Total \\
\hline $\mathrm{f}$ & 4 & 2 & 6 & 4 & 14 & 30 \\
\hline$\%$ & 13,2 & 6,6 & 19,8 & 13,2 & 46,2 & 100 \\
\hline
\end{tabular}

As shown in the table $12,60 \%$ of audiences think that they can do Soundpainting. Soundpainting offers to opportunity in every age, every human being to improvise and participate in performance. 
Table 13. Responses of the listeners to the statement "I would like to go to a concert with the soundpainting performance again"

\begin{tabular}{ccccccc}
\hline & Excessive & Quite & Partly & Few & None & Total \\
\hline $\mathrm{f}$ & 18 & 9 & 3 & - & - & 30 \\
\hline$\%$ & 59,4 & 29,7 & 9,9 & - & - & 100 \\
\hline
\end{tabular}

As shown in the table 13, as many as $90 \%$ of audiences say they want to go to a Soundpainting concert again.

Table 14. Responses of audiences to "Soundpainting sign language is a powerful tool for communication "

\begin{tabular}{ccccccc}
\hline & Excessive & Quite & Partly & Few & None & Total \\
\hline $\mathrm{f}$ & 1 & 4 & 2 & 2 & 21 & 30 \\
\hline$\%$ & 3,3 & 13,2 & 6,6 & 6,6 & 69,3 & 100 \\
\hline
\end{tabular}

As shown in the table 14, 76\% of audiences do not think Soundpainting is a powerful tool for communication.

Table 15. Responses of audiences to "Soundpainting sign language can improve social communication"

\begin{tabular}{ccccccc}
\hline & Excessive & Quite & Partly & Few & None & Total \\
\hline $\mathrm{f}$ & 8 & 7 & 11 & 1 & 3 & 30 \\
\hline$\%$ & 26,4 & 23,1 & 36,3 & 3,3 & 9,9 & 100 \\
\hline
\end{tabular}

As shown in the table 15, we can say that audiences regard Soundpainting as a stage art that allows people from all ages and all walks of life to improvised music by collecting under the same roof.

How are the audiences handling the Soundpainting performance in terms of musical dimension? Findings related to fifth sub-problem

Two questions were asked to participants to answer this sub-question.

Table 16. Responses of audiences to the statement "The technical skill is at the forefront in Soundpainting performance".

\begin{tabular}{ccccccc}
\hline & Excessive & Quite & Partly & Few & None & Total \\
\hline $\mathrm{f}$ & 5 & 10 & 9 & 5 & 1 & 30 \\
\hline$\%$ & 16,5 & 33 & 29,7 & 16,5 & 3,3 & 100 \\
\hline
\end{tabular}

As shown in the table $16,50 \%$ of audiences think that the technical skill is at the forefront in Soundpainting performance.

Table 17. Responses of audiences to the statement "The musical experience is at the forefront in Soundpainting performance".

\begin{tabular}{ccccccc}
\hline & Excessive & Quite & Partly & Few & None & Total \\
\hline $\mathrm{f}$ & 9 & 10 & 5 & 6 & - & 30 \\
\hline$\%$ & 29,7 & 33 & 16,5 & 19,8 & - & 100 \\
\hline
\end{tabular}

As shown in the table 17, 63\% of audiences think that musical experience is even more forefront in Soundpainting performance.

\section{Conclusion}

According to the data obtained for the first sub-problem, Soundpainting performance reflects today's experience. In the light of this result, we can say that audiences establish an organic relation between Soundpainting and life. According to Oskay (2001), "music; must demonstrate and represent contradictions in the society in which they exist in their material and in their formal rules (in accordance with their own circumstances and requirements)" (Cited. Türkmen, 2012: 805). Soundpainting is a stage art that is free, aleatoric, boundless, interactive with the audience and open to surprises. Being open to these surprises saves the listeners from the ordinary and makes performance more enjoyable.

According to the data obtained for the second sub-problem, audiences are happy and feel free in the Soundpainting performance. In addition to this, the music that emerged in Soundpainting performance does not make the audiences angry and does not get into a tense situation. Soundpainting is not a stage art that fasten audiences to the seat like some of musical genres. Today's audiences, who are sensitive about ownership of time, prefer performances that do not last very long and will be an active place instead of self-limiting performances. For this reason, audiences feel themselves psychologically positive in Soundpainting performance.

According to the data obtained for the third sub-problem, audiences find Soundpainting performance as aesthetically beautiful, useful and universal. Philosophers have made many statements throughout history about what beauty is. There are also psychological evaluators as well as metaphysical notions that take on a good idea, an ideal. German philosopher Theodor Lipps; expresses "beautiful" as a form that a person feels pleasure and feels free (Ergün, 2008: 6). According to this understanding, audiences find Soundpainting nice because they feel free. 
According to the data obtained for the fourth sub-problem, audiences involved in the Soundpainting performance think they can do soundpainting. Also, audiences want to go Soundpainting concert again and want to take part in a Soundpainting collective. One of the important elements of socialization is the ability to interact with people we live together with. Soundpainting offers the possibility to make music together with anyone who speaks this language and allows us to socialize with people in communication.

According to the data obtained for the fifth sub-problem, audiences think that both technical and musical skills are necessary in Soundpainting performance. Soundpainting is an art that incorporates improvisation in its structure. Soundpainting gives everybody the opportunity to make music as much as their technical and musical background. However, performers with more musical knowledge and skills can naturally perform more sophisticated and conscious performances.

\section{References}

Akarsu, B. (1975). Glossary of Philosophical Terms. Ankara: Turkish Language Institution Publishing.

Coşkuner, S. (2016). Effects of Soundpainting Lesson in Increasing the Motivation for Listening to Aleatoric Music. Middle East Journal of Scientific Research, 24(1), 15-21.

Dürük, E. F. (2009). The Place Of Tradition And Audience Factor Through Modern Music Composers's Innovation Searchings. Süleyman Demirel University ocial Science Institution Journal, 1(9), 207-216.

Ergün, M. (2008). Art Philosophy (Aesthetic). Afyon Kocatepe University Education Faculty Lecture Notes. Date of access: 07.07.2018. http://mustafaergun.com.tr/wordpress/wp-content/uploads/2015/11/sanatfelsefesi.pdf

Göncü, İ. Ö. (2018). Thoughts Behaviors of Parents on Motivating Their Children Aged 4-6 for Music. Journal of Education and Training Studies, 6(9), 46-52. https://doi.org/10.11114/jets.v6i9.3340

Ikonomova, V. (1972). Music and the Audience. International Review of the Aesthetics and Sociology of Music, 3(1), 1121-1126.

Kalender, N. (2001). Educational Foundations of Music Listening. Uludağ Universityi Education Faculty Journal, XIV(1), 147-157.

Karasar, N. (2004). Scientific Research Method. (13th ed.) Ankara: Nobel Publishing.

Senemoğlu, N. (2004). Development Learning and Teaching. Ankara: Gazi Bookstore

Subaşı, G. (2011). Education Psychology. Ankara: Anı Publishing.

Thompson, W. (2015). Soundpainting Workbook I. New York.

Türkmen, U. (2012). No Voice No Musical Perception? To Perceive The 4'33. III. International Hisarli Ahmet Symposium. Kutahya, 804-812.

Yöre, S. (2011). Contemporary Music: The Mainstreams, The Techniques Of Musical Composition And Principal Composers. Çukurova Üniversitesi Sosyal Bilimler Enstitüsü Dergisi, 20(3), 1-20.

\section{Copyrights}

Copyright for this article is retained by the author(s), with first publication rights granted to the journal.

This is an open-access article distributed under the terms and conditions of the Creative Commons Attribution license which permits unrestricted use, distribution, and reproduction in any medium, provided the original work is properly cited. 